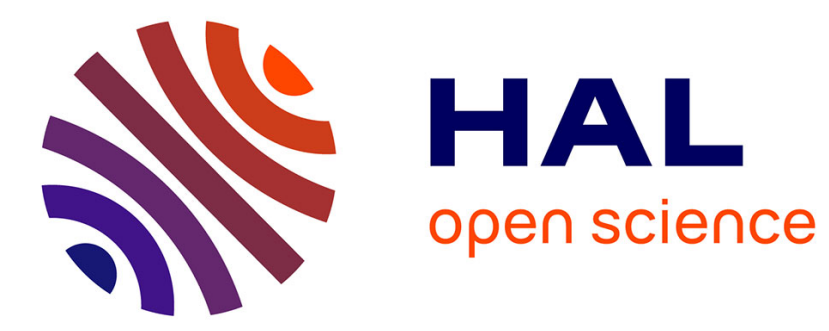

\title{
The impact of architecture on collective behaviour
}

\author{
Noa Pinter-Wollman, Stephen M Fiore, Guy Theraulaz
}

\section{To cite this version:}

Noa Pinter-Wollman, Stephen M Fiore, Guy Theraulaz. The impact of architecture on collective behaviour. Nature Ecology \& Evolution, 2017, 1 (5), 10.1038/s41559-017-0111 . hal-02324034

\section{HAL Id: hal-02324034 \\ https://hal.science/hal-02324034}

Submitted on 4 Oct 2021

HAL is a multi-disciplinary open access archive for the deposit and dissemination of scientific research documents, whether they are published or not. The documents may come from teaching and research institutions in France or abroad, or from public or private research centers.
L'archive ouverte pluridisciplinaire HAL, est destinée au dépôt et à la diffusion de documents scientifiques de niveau recherche, publiés ou non, émanant des établissements d'enseignement et de recherche français ou étrangers, des laboratoires publics ou privés. 

32826 USA (sfiore@ist.ucf.edu) Cedex 9, France. (guy.theraulaz@univ-tlse3.fr)

11 Abstract: Collective behavior emerges from social interactions among group members. Despite the obvious

12 influence of space on interactions, constraints imposed by the built environment are seldom considered when examining collective behaviors of animals and humans. We propose an interdisciplinary path towards uncovering the impact of architecture on collective outcomes.

17 interact. The former has dominated much of the discussion in the literature ${ }^{1}$. But, as the study of collective behavior expands, it is time to elucidate the role of the built environment in shaping collective outcomes.

21 spatial proximity is necessary for an interaction to occur, spatial constraints are rarely considered in studies of

22 collective behavior. An interdisciplinary exchange between behavioral ecologists, evolutionary biologists, cognitive

23 scientists, and architects may facilitate a productive exchange of ideas, methods, and theory that could lead us to uncover unifying principles and novel research approaches and questions in studies of animal and human behavior. 
27 increased understanding of the effects of structural constraints on interactions is now possible because of new tracking tools used in conjunction with complex network theory (Box 1). Here we suggest research questions that will benefit from both interdisciplinary exchange and recent technological advances. structures influence the efficiency of collective behavior in animals and collective cognition in humans. Biologists have found that the speed at which harvester ants recruit to food increases with the connectivity of nest chambers ${ }^{4}$ and that obstructions near the nest exit of ants facilitate rapid evacuation when in distress ${ }^{5}$. Social scientists have found that the layout of buildings affects scientific collaborations ${ }^{6}$ and innovation ${ }^{7}$. Despite conceptual

37 similarities among these research communities, there has been little, if any, cross-disciplinary communication. Although there are differences among organisms that occupy built structures (e.g., social insects prefer dark spaces and humans prefer light), there are functional similarities, such as the need to coordinate activities and collaborate, which can be extended from one discipline to inform the other. In particular, examining the behavior of animals lends itself to conducting experimental manipulations that are not feasible with human societies. Thus, testing and manipulating social structures and group interactions in social animals, may provide insights on the causative relationships between certain architectural features and collective outcomes that can then be used to improve the efficiency of human societies.

47 When group members interact to produce collective outcomes there is information exchange and processing. Physical structures can serve an important functional role in this information processing. First, structures can help manage the volume and diffusion of information. Larger spaces afford greater amounts of information to be 
51 individuals to shut down and reduce interactions with their surroundings ${ }^{8}$. Thus, structures that segregate

52 individuals (e.g., chambers and tunnels), may reduce stimuli and help filter unnecessary information. Second,

53 certain spatial cues, such as the chemical trails of social insects and road signs in human transportation networks,

54 can aid in the interpretation and use of information. Such cues in the environment can help avoid information overload by externalizing knowledge that can then be used as a scaffold for further information building. Despite the economic implications of such structures (furniture, signs, obstacles etc.) on work productivity in humans,

57 there has been little quantitative research on how spatial layouts and physical artifacts can influence collective 58 information processing. By manipulating spatial signals and physical obstacles to examine their impact on the 59 collective actions of social animals, we can develop new, biologically inspired, means to improve information 60 processing in humans.

Structures are not formed in a vacuum, there is intricate feedback between the architecture of a structure, its residents, and the external environment. Structures are constantly renovated: nest remodeling in social insects 65 allows colonies to alter gas exchange dynamics ${ }^{9}$ and respond to changes in colony size ${ }^{10}$. Thus, there is constant feedback between a structure and the needs of the individuals that reside in it. Engineers study the constraints

67 that built structures are subjected to by the physical attributes of the materials used for construction. We argue 68 that the social activities taking place in these structures should also be considered when designing structures. 69 Currently, we know very little about how the functional needs of a group influences their built structures and 70 changes to it over time. Testing the bi-directional relationship between built structures and collective behaviors in 71 social animals can be as simple as examining the architecture of structures animals build when subjected to 72 different environmental constraints to facilitate the most effective collective outcomes. Such work with social 73 animals can rapidly explore a wide array of environments and outcomes, thus expediting our improvement of 74 human architectural design. 
77 Interdisciplinary work on architecture and collective behavior may uncover new biomimicry concepts ${ }^{11}$ that will 78 create synergies among biologists, social scientists, physicists, engineers, and architects. Uncovering general 79 principles that describe the impact of architecture on collective behaviors has far reaching implications. Most 80 basically, understanding the effect of structures on the collective behavior of social animals may reveal important

81 fitness consequences. Furthermore, the scientific understanding of how building architecture influences human 82 interactions can be used to scaffold collaborations that drive innovation. But there is a greater opportunity for 83 scientific advances when considering interdisciplinary research that enables studies across multiple species.

84 Lessons from biology may help formalize the quantification of spaces and uncover architectural features that will optimize their impact on collaboration. For example, studies on the location of spaces that are used for communication in social insects (e.g., dancing floor in bees ${ }^{12}$, entrance chamber in ants ${ }^{13,14}$ ) may inform the positioning of such features, such as water coolers, which are informal spaces that facilitate the spread of tacit knowledge, in human buildings. Uncovering how the collective behaviors of social animals are influenced by their built structures may improve human architectural design and enhance innovations that result from team work by learning from structures that have been selected by millions of years of evolution. By initiating a cross-disciplinary conversation we hope to inspire further research on the relationship between architecture and collective behavior.

Although methods for quantifying structures are essential for examining how structures affect collective outcomes, we currently lack a diverse quantitative tool-box. Network representations have proven extremely useful for

97 describing the arrangement of structures in studies of social insects ${ }^{4,15,16}$ and humans $6,17,18,19$. However, further development of algorithms that translate structures into networks, and of relevant network measures, are still needed to expand this line of research. Furthermore, when chambers or rooms are difficult to define (e.g., in an art 
gallery), networks may not be suitable. One possible solution is skeletonization which reduces complex 3D

101 structures to emphasize their geometrical and topological properties (Figure $1,{ }^{25}$ ). A glaring methodological gap is

102 our inability to combine the quantification of both topology and volume of structures into a single variable.

103 Measuring the volume of structures at different depths ${ }^{20-22}$ may provide information on the amount of space that

104 can be utilized but it holds no information on structure topology. Likewise, an examination of network

105 representations of structures holds no information on their volume. Finding ways to jointly quantify topology and

106 volume is an interdisciplinary challenge that calls for cross-disciplinary collaborations to develop tools and

107 formulas capable of testing the utility and generalizability of such approaches.

Once we quantify architectural features, we require methods for examining the movements and interactions of the occupants of these spaces. Specifically, there is need for methods to quantify the relationship between movements and the resulting social interactions and various spatial constraints. The use of sensor technologies, such as tracking devices, provides ample spatial data that can be analyzed in similar ways across

112 systems. Extracting information on interactions from movement patterns in ants ${ }^{23}$ and humans ${ }^{24}$ has uncovered 113 similar interaction patterns within confined spaces. Advances in materials engineering to create devices that are 114 capable of capturing simultaneously information transfer and movement patterns will allow for studies on both 115 the form and content of information transfer across different spatial scales and in different species.

117 Figure 1: An example of the skeletonization of a termite nest (Trinervitermes geminatus): (a) a picture of the nest;

118 (b) a tomographical slice of the nest; and (c) the network of tunnels in the nest in which edges are colored 119 according to their value of betweenness centrality. The technique used to extract this network is based on ${ }^{25}$. 


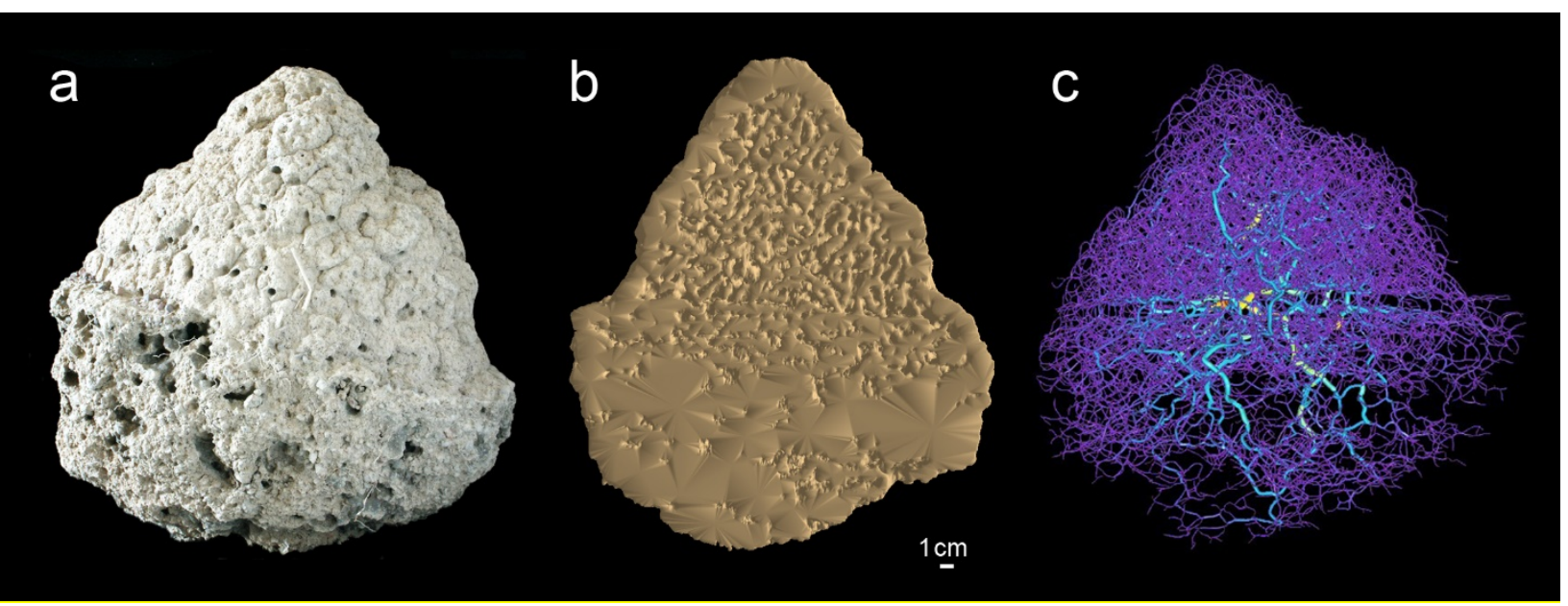

121

1251 Hansell, M. H. Built by animals : the natural history of animal architecture. (Oxford University

$126 \quad$ Press, 2007).

1272 Gordon, D. M. Ant encounters: Interaction networks and colony behavior. (Princeton University

128 Press 2010).

1293 Fiore, S. M. \& Salas, E. in Team Cognition: Understanding the factors that drive process and performance (eds E. Salas \& S.M. Fiore) 235-248 (American Psychological Association, 2004). Pinter-Wollman, N. Nest architecture shapes the collective behavior of harvester ants. Biology Lett, 20150695, doi: http://dx.doi.org/10.1098/rsbl.2015.0695 (2015).

1335 Burd, M., Shiwakoti, N., Sarvi, M. \& Rose, G. Nest architecture and traffic flow: large potential effects from small structural features. Ecological Entomology 35, 464-468, doi:10.1111/j.13652311.2010.01202.x (2010).

6 Kaffects on the dynamics and outcomes of scientific collaborations. Res Policy 43, 1469-1485, doi:DOI 10.1016/j.respol.2014.04.007 (2014).

1397 Wineman, J. D., Kabo, F. W. \& Davis, G. F. Spatial and Social Networks in Organizational Innovation. Environ Behav 41, 427-442, doi:10.1177/0013916508314854 (2009). (Oxford University Press, 2009). Korb, J. Thermoregulation and ventilation of termite mounds. Naturwissenschaften 90, 212-219, doi:10.1007/s00114-002-0401-4 (2003). 
14811 Holbrook, C. T. et al. Social insects inspire human design. Vol. 6 (2010).

14912 Seeley, T. D. \& Towne, W. F. Tactics of Dance Choice in Honey-Bees - Do Foragers Compare

150 Dances. Behavioral Ecology and Sociobiology 30, 59-69 (1992).

$151 \quad 13$ Pinter-Wollman, N., Wollman, R., Guetz, A., Holmes, S. \& Gordon, D. M. The effect of individual

152 variation on the structure and function of interaction networks in harvester ants. Journal of the

153 Royal Society Interface 8, 1562-1573, doi:DOI 10.1098/rsif.2011.0059 (2011).

15414 Pinter-Wollman, N. et al. Harvester ants use interactions to regulate forager activation and availability. Anim Behav 86, 197-207, doi:10.1016/j.anbehav.2013.05.012 (2013).

15615 Buhl, J., Deneubourg, J. L., Grimal, A. \& Theraulaz, G. Self-organized digging activity in ant colonies. Behavioral Ecology and Sociobiology 58, 9-17, doi:DOI 10.1007/s00265-004-0906-2 (2005).

16217 Penn, A. Space syntax and spatial cognition - Or why the axial line? Environ Behav 35, 30-65, doi:10.1177/0013916502238864 (2003).

$16418 \quad$ Barthelemy, M. Spatial networks. Phys Rep 499, 1-101, doi:DOI 10.1016/j.physrep.2010.11.002

165 (2011). of Insect Science 21, 1-19 (2004). badius: distribution of workers, brood and seeds within the nest in relation to colony size and season. Ecological Entomology 24, 222-237, doi:DOI 10.1046/j.1365-2311.1999.00184.x (1999). Cerquera, L. M. \& Tschinkel, W. R. The nest architecture of the ant Odontomachus brunneus. Journal of Insect Science 10 (2010). and social interactions in insects. J Exp Bio/ 214, 17-21, doi:10.1242/jeb.050526 (2011). 